\title{
Identifying the Challenges of Iran's Health Houses and Presenting a Solution
}

\author{
Seyed Hossein Saberi ${ }^{1}$, Mostafa Alimehr ${ }^{2}$, Mohammadreza Amiresmaili ${ }^{3}$, Maryam Seyednezhad ${ }^{2}$
}

${ }^{1}$ Ph.D., Assistant Professor, Health Services Management, Policy and Economics Department, School of Management and Medical Informatics, Kerman University of Medical Sciences, Kerman, Iran

${ }^{2}$ M.Sc., Health Services Management, Policy and Economics Department, School of Management and Medical Informatics, Kerman University of Medical Sciences, Kerman, Iran

${ }^{3}$ Ph.D., Associate Professor, Medical Informatics Research Center, Institute for Futures Studies in Health, Kerman University of Medical Sciences, Kerman, Iran

\section{Type of article: Original}

\begin{abstract}
Introduction: After more than three decades of network system design, epidemiological transition, as well as the change in needs and expectations of rural communities, have brought some challenges for Iran's health houses. So, this study is aimed at identifying these challenges through a qualitative study.

Methods: This was a qualitative and phenomenological study which was carried out in three phases in Iran in 2015. In the first phase, the required data was collected through semi-structured interviews with selected experts, health workers and referrals to Iran's health houses, so that all were selected purposefully. In the second phase, two expert panels were conducted to provide solutions. In the third phase the strengths, weaknesses, opportunities and threats were evaluated using the Strengths, Weaknesses, Opportunities, Threats (SWOT) method. The data of the first two phases were analyzed using the Collaizi method.

Results: Fourteen subthemes under five themes of ; quality of provided services, human resources, infrastructure, inter-sectorial and intra-sectorial relations, and contextual factors were identified as the challenges of Iran's health houses, and consist of fourteen sub themes. Continuous education of health workers, equipping and renovating old buildings, improving inter and intra-sectorial relationships and the proportionating workload with a number of workers, were the most important solutions.

Conclusion: The study showed that, over time, many of the functions of Iran's health houses have been faced with problems, therefore, training the manpower, equipping Iran's health houses and creating better public spaces and building culture are recommended to enhance the effectiveness and revisions based on the study.

Keywords: Iran's health houses, Challenge, Primary health care
\end{abstract}

\section{Introduction}

In all Communities, health has been identified as a fundamental right of every one and the governments are responsible to satisfy it (1). Easy and inexpensive access of patients to health care centers is considered as one of the most important criteria of evaluating the health care system (2). The health care systems in many countries are trying to achieve three objectives of reducing the share of people in health expenditures, improving health and ensuring high quality services (3). Since many years ago, the need to provide quick and easy access to basic health needs was felt by Iran's health authorities, who implemented different projects such as worker training, health plan, and the Rezaieh plan aimed at ensuring the population had access to basic health needs (4). Lessons learnt from these projects coupled with the WHO's Alma-Ata declaration in 1978, which put the health for all by the year 2000 in the WHO's country members agenda, accelerated Iran's health network design (4). According to Iran's health network, health houses and (rural and urban) health centers are considered as the first level of providing health services with

\section{Corresponding author:}

Mostafa Alimehr, Health Services Management, Policy and Economics Department, School of Management and Medical Informatics, Kerman University of Medical Sciences, Kerman, Iran.

Tel: +98.3431325165, Fax: +98.3431325221, Email: mostafaalimehr62@gmail.com

Received: May 18, 2016, Accepted: July 25, 2016, Published: October 2016

iThenticate screening: July 24, 2016, English editing: August 26, 2016, Quality control: September 18, 2016

(C) 2016 The Authors. This is an open access article under the terms of the Creative Commons Attribution-NonCommercialNoDerivs License, which permits use and distribution in any medium, provided the original work is properly cited, the use is non-commercial and no modifications or adaptations are made. 
close contact with people (5). Evidence shows that effective primary health care had many advantages such as improving health-care outcomes, reducing health gaps, improving equitable access to care and ensuring quality care with lower costs (6). After a period of relative ignorance, in recent years, interest and reconversion has risen to primary health care, especially in low and middle-income countries (7). According to a World Health Report in 2008, the society's response to the challenges of primary health care is not satisfactory due to failure to mobilize resources, undue concentration on specialist hospital care, and scattered and heterogeneous health systems (8). Typically, the effectiveness of primary health care is evaluated by its contribution to the achievement of health system goals such as better health, fair access to services, accountability and financial protection. However, today's health systems, even in the most developed countries, are failing in achieving these objectives (9). With changing demographic and epidemiological factors changing people's expectations and level of education, especially literacy and expectations of rural women, change in people's views about the quality of provided services, as well as the fact that, Iran's Health network system was developed almost three decades ago, there is need to change existing technologies, and financial pressure to the government to meet the needs of the growing necessity to review the structure, quality and quantity of services provided, and the revision of the process of providing health services in Iran's health houses (10). Therefore this study is aimed at identifying challenges of health houses and to provide solutions to overcome them.

\section{Material and Methods}

The present study was a qualitative study using a phenomenology approach which was carried out at nationwide during 12 months from February 2015 to February 2016. The study population included policy makers, experts of the Ministry of Health, scholars and experts involved in the primary health care system in the country, heads of medical universities, authorities and health assistants in the provinces and physicians, health workers and the clients in the cities. Purposive sampling methods through criteria such as having key information in the field of primary health care (especially health houses), and having at least 5 years executive experience in the field of health, was used to identify informant participants and to achieve a more informed sample, and was completed by the snowball sampling method. Sampling was continued until it reached data saturation i.e. the point when no new information was expressed by new participants. Qualitative data were collected through Semi-structured and in-depth interviews and holding expert panels. All the interviews were recorded and transcribed. To analyze data the Colaizzi method was used, which is mostly related to phenomenological qualitative data analysis studies. It includes seven stages of familiarization with the general concepts of: extracting important statements and determining key areas (themes), formulating concepts and central statements, themes and categorization of main concepts and explaining themes, being the main structure extraction, and validation of study. All these steps were done manually by the researcher and without the use of special software.

\section{Results}

The number of interviewees was 24, and of this number, 19 persons were men and 5 persons were women. The average age of respondents was 45 years, and the average experience in the field of administration and management was 20 years. Each interview was done for approximately 35 minutes. The average work experience of health workers interviewed was 15 years.

\subsection{Quality of service}

The creation of new government initiatives in the field of health, and the creation of applications injected into the healthcare system, may increase the expectations of society to receive better quality services. The core axis consists of two sub-axes as follows:

1) The mismatch of services quality with educational level of health workers

2) The relevance of quality of service with clients' expectations.

A number of interviewees in this regard stated: "Health workers should upgrade their education, and must be updated on Iran's health houses"

\subsection{Manpower}

Of the quantitative and qualitative terms, (because of the major changes that have occurred during the past three decades), manpower is one of the main challenges for Iran's health houses. It also includes four sub-axes, as follows: 1) The mismatch of human resources with manpower, 2) Conflict between work life and family life of health workers, 3) Lack of motivation and job promotion for health workers, 4) Acceptance rate decline and demotion of health workers in the community. A number of interviewees in this regard stated: 
"From a quantitative point of view, the number of services that are being offered at Iran's health houses has increased, but is not defined according to human resources, and it is in need of review in the discussion of manpower in Iran's health houses"

\subsection{Infrastructures}

In this regard, unfortunately, Iran's health houses have received little attention and do not have enough facilities. The main axis also has three sub-axes as follows: Physical space, Technology, Equipment. A number of interviewees in this regard stated: "Measuring instruments don't have the necessary quality, and have a short shelflife" (M 3)

\subsection{Integrand Intra-sectoral relationships}

It is considered as one of the important principles of PHC to the success of Iran's health houses, it also has three sub-axes, which are as follows: 1) Support by insufficient upstream references, 2) The weakness of inter-sectorial relationship, 3) The weak collaboration between different parts. A number of interviewees in this regard stated: "We travel there from a long distance and there might not be supervisor, or they do not have time, and have no time for health workers, subsequently health house work may be delayed." (May 13).

\subsection{Underlying factors}

In recent years, issues such as: epidemiological transition, demographic transition and an aging population, along with the incidence of non-communicable diseases, the increasing trend towards urbanization have faced Iran's health houses with basic challenges. This also includes two-axes, which are: 1) Migration from rural to urban areas, 2) Increasing levels of education and expectations. Interviewees in this regard expressed their statements as follows: "The problems of Iran's health houses are related to increasing number of health workers who want to migrate to the city to have access to better facilities" (M 4). "Day after day, the literacy of our population has increased and our expectations have increased, but in the past, since people did not have much information, their expectations were less, but over time, their expectations have increased" (AD 7).

\section{Discussion}

The results show the challenges and major problems of the Iranian health houses in different aspects. Major challenges include challenges related to the quality of health services provided at health houses, the challenges related to manpower, challenges related to equipment, technology and financial resources, inter-sectorial and intrasectorial relations, and challenges related to the underlying Infrastructure.

\subsection{The quality of service}

Based on the findings of interviews with experts, issues such as the promotion of education and the expectations of society have led to the dissatisfaction of referrers with the quality of services provided in health houses. Since network system design and Iran's health houses are related to three decades ago, and at that time, education level and knowledge of the rural population was low, currently, the quality of health services provided at Iran's health houses, in some cases are not responsive to the expectations of visitors. Mohammad Alizadeh et al., in 2010, studied the barriers related to high quality primary health care services in a metropolitan area in Iran, using the perspective of public health care service providers. The low quality of primary health care, resulting in employee dissatisfaction arose as factors outside of their control and organizational barriers; in fact, this study highlights the role of training staff in providing high quality primary health care services (11).

\subsection{Manpower}

In terms of manpower, one of the challenges mentioned by experts in this field is the issue of population migration. Now, for reasons such as lack of amenities in the countryside, as well as the tendency of people to urbanization, most of the villagers migrate to the city. Davoudi et al., in 2007, in an article entitled "Introduction to the health care system" identified the shortage of people who manage these systems as the most critical issue facing health care systems. Health systems based on primary health care must deal with the key challenges in the field of maintaining the man power, information management, financing in the health sector and fair production - and with emphasis on manpower as a key factor, must take necessary measures to achieve the goals of health system (12).

\subsection{Infrastructures}

In terms of infrastructures, major problems in three areas of equipment, technology and physical space are proposed. Based on interviews, investment in the health sector has been inadequate, and there has not been enough attention to 
this area. Regarding the challenges and problems in the field of equipment, most interviewees believed that equipment was basic and inexpensive for Iran's health houses, and home health, because first contact level, and the first referral level in the network, does not require complex and expensive equipment. However, existing worn and old equipment, or lack of some equipment are the main issues and challenges in this field, which requires attention and management. Samir et al., in a study entitled "Challenges and Opportunities Related to Integration of Primary Health Care Information System: The Northern State of Sudan" in 2010 showed that primary health care information system plans are inadequate and ineffective to provide quality information to support the managers in the decision making process. The main problems of the system include lack of proper infrastructure, lack of skilled specialists, working in parallel, lack of coordination, a lack of supervision and support, and feedback to lower levels, which are effective in the poor performance of the system (13).

\subsection{Inter-sectoral relations}

According to the opinions of experts, weak oversight, poor referral systems, a poor reporting system, lack of psychological support and adequate support of upstream references, and the absence of adequate feedback to health workers are considered as the main challenges and problems in the field of inter-sectorial relations. Mahryar, in an article titled "Primary Health Care and poor villages in the Islamic Republic of Iran in 2004"introduced the most important challenges and problems facing the Iranian health houses as follows: Lack of adequate support for secondary and tertiary levels of health houses, lack of adequate government support of Iran's health houses in the physical space and equipment, the lack of an integrated policy in connection with private sector units and centers of training health workers, and the lack of a stable mechanism to improve the quality of services (14).

\subsection{Intra-sectorial relations}

Lack of timely cooperation with the concerned authorities, and other organizations with health workers, and lack of timely follow-up and implementation of reported cases are the most important challenges mentioned in this field. In a study conducted by Asadi et al in 2004, entitled "Primary Health care Experiences in Iran", the list of challenges on the primary health care system is presented (15).

\subsection{Underlying factors}

The distribution pattern and population distribution, and the climatic and geographical conditions of the country, increasing trend towards urbanization, education and changing attitudes and expectations of people, lack of sufficient attractions in villages, migration and demographic changes in rural areas, lack of adequate welfare infrastructure facilities in villages, demographic and epidemiological transition, and the changing pattern of diseases are considered as the most important underlying challenges and infrastructure, which the health house has been faced with Nekoeimoghadam et al. (2011), study showed that, although primarily healthcare service in Iran between 1970 and 1980 is in accordance to the needs of Iranian society, changes in the burden of diseases and changes in demand of population has led to the opinion that the desired system doesn't have the ability to respond to new needs of the present time. Although, Iran's primary health care system to respond has been successful to infectious diseases and maternal and newborn deaths, it seems that, it has been faced with some problems in response to noncommunicable diseases (16).

\section{Conclusions}

This study identified main challenges facing health houses of Iran. The practical significance of these findings for the policy makers and the ministry of health authorities is that, they should revise the health houses from different aspects such as human resources, equipment and information systems. These revisions will enable the health houses to continue to play their vital role as the entry and the first contact of Iran's health system. Future studies should focus on issues such as measuring the workload of health houses and to evaluate the efficacy of health houses' human resources to meet all defined tasks and duties.

\section{Acknowledgments:}

Herein, we kindly thank all the anonymous participants who provided us their valuable experiences. We also thank the authorities of the Ministry of Health as well as different medical universities who did their best to make this study possible. This study was a part of an MSC thesis which was funded by the Deputy for Research and Technology of Kerman University of Medical Sciences.

\section{Conflict of Interest:}

There is no conflict of interest to be declared. 


\section{Authors' contributions:}

All authors contributed to this project and article equally. All authors read and approved the final manuscript.

\section{References:}

1) Park K. Park's Textbook of preventive and social medicine. 18th edition. Banarsidas Bhanot Publishers. $2005 ; 1-2$.

2) Baker R. Development of a questionnaire to assess patients' satisfaction with consultations in general practice. Br J Gen Pract. 1990; 40(341): 487-90. PMID: 2282225, PMCID: PMC1371443.

3) Starfield B, Shi L, Macinko J. Contribution of primary care to health systems and health. Milbank Q. 2005; 83(3): 457-502. doi: 10.1111/j.1468-0009.2005.00409.x. PMID: 16202000, PMCID: PMC2690145.

4) Marandi A. Integrating medical education and health services: the Iranian experience. Med Educ. 1996; 30(1): 4-8. doi: 10.1111/j.1365-2923.1996.tb00709.x. PMID: 8736181.

5) Azizi F. The reform of medical education in Iran. Med Educ. 1997; 31(3): 159-62. doi: 10.1111/j.13652923.1997.tb02559.x. PMID: 9231131.

6) Takian A, Rashidian A, Kabir MJ. Expediency and coincidence in re-engineering a health system: an interpretive approach to formation of family medicine in Iran. Health Policy Plan. 2011; 26(2): 163-73. doi: 10.1093/heapol/czq036. PMID: 20732859.

7) Liu X, Hotchkiss DR, Bose S. The effectiveness of contracting-out primary health care services in developing countries: a review of the evidence. Health Policy Plan. 2008; 23(1): 1-13. doi: 10.1093/heapol/czm042. PMID: 17999986.

8) World Health Organization. The world health report 2003: shaping the future. World Health Organization. 2003.

9) Kruk ME, Porignon D, Rockers PC, Van Lerberghe W. The contribution of primary care to health and health systems in low-and middle-income countries: a critical review of major primary care initiatives. Soc Sci Med. 2010; 70(6): 904-11. doi: 10.1016/j.socscimed.2009.11.025. PMID: 20089341.

10) Zanganeh Baygi M, Seyedin H. Imbalance between goals and organizational structure in primary health care in Iran-a systematic review. Iran J Public Health. 2013; 42(7): 665-72. PMID: 24427745, PMCID: PMC3881612.

11) Mohammad-Alizadeh CS, Wahlström R, Vahidi R, Nikniaz A, Marions L, Johansson A. Barriers to highquality primary reproductive health services in an urban area of Iran: views of public health providers. Midwifery. 2009; 25(6): 721-30. doi: 10.1016/j.midw.2008.01.002. PMID: 18325645.

12) Davoodi S. [An introduction to health systems]. asare moaaser press, Tehran. 2006.

13) Farah SK. Challenges and Opportunities of Integrating Primary Health Care Information System: Northern State, Sudan. Doctoral dissertation, University of Oslo. 2011.

14) Mehryar A. Primary health care and the rural poor in the Islamic Republic of Iran. In Scaling Up Poverty Reduction: A Global Learning Process and Conference Shanghai. 2004; 25-7.

15) Asadi-Lari M, Sayyari AA, Akbari ME, Gray D. Public health improvement in Iran-lessons from the last 20 years. Public health. 2004; 118(6): 395-402. doi: 10.1016/j.puhe.2004.05.011. PMID: 15313592.

16) Moghadam MN, Sadeghi V, Parva S. Weaknesses and challenges of primary healthcare system in Iran: a review. Int J Health Plann Manage. 2012; 27(2): 121-31. doi: 10.1002/hpm.1105. PMID: 22009801. 